\title{
A comunicação aumentativa e alternativa para a aprendizagem: estudo de caso de um aluno com surdocegueira congênita
}

Augmentative and alternative communication for learning: case study of a student with congenital surgery

Elzinete Maria Carvalho Machado

Desirée Gonçalves Raggi

Resumo: O estudo objetiva avaliar as contribuições da estratégia pedagógica Comunicação Aumentativa e Alternativa (CAA) para o ensino-aprendizagem de um aluno com surdocegueira congênita. A educação de pessoas com surdocegueira ainda é um tema pouco investigado no Brasil e no Estado. Trata-se de estudo de caso que utilizou práticas pedagógicas com materiais táteis para promover o processo educacional do sujeito. Para tanto, foram realizadas previamente a observação e entrevista com a mãe e professores, a fim de compreender seu comportamento no âmbito familiar e como se processa seu desenvolvimento educacional. A intermediação com a materiais pedagógicos adaptados foram fundamentais para que o indivíduo desenvolvesse a percepção de mundo e melhorasse sua comunicação. Os resultados da pesquisa foram alcançaram seus objetivos, pois o aluno estabeleceu formas de CAA, Libras tátil, interpretação háptica, braille, noção de tempo, regras de convivência, afetividade, conceitos pessoais e sociais. Os resultados da pesquisa evidenciaram que a intervenção pedagógica com o uso da CAA contribuiu para a aprendizagem do aluno com surdocegueira congênita. Importante considerar a extrema relevância em estabelecer a participação ativa do aluno, em todas as fases da intervenção.

Palavras-chave: Surdocegueira; Instrutor Mediador; Deficiência; Comunicação Aumentativa e Alternativa.

Abstract: The study aims to evaluate the contributions of the pedagogical strategy Augmentative and Alternative Communication (CAA) to the teaching-learning of a student with congenital deafblindness. The education of people with deafblindness is still a topic little investigated in Brazil and in the State. This is a case study that used pedagogical practices with tactile materials to promote the subject's educational process. To this end, observation and interviews were carried out with the mother and teachers in order to understand their behavior in the family and how their educational development takes place. Intermediation with adapted teaching materials was essential for the individual to develop the perception of the world and improve their communication. The results of the research were achieved, as the student established forms of CAA, Libras tactile, haptic interpretation, braille, notion of time, rules of coexistence, affectivity, personal and social concepts. The results of the research showed that the pedagogical intervention with the use of CAA contributed to the learning of the student with congenital deafblindness. It is important to consider the extreme relevance in establishing the active participation of the student, in all phases of the intervention.

Keywords: Deafblindness; Mediating Instructor; Deficiency; Augmentative and Alternative Communication. 


\section{Introdução}

A pesquisa foi realizada em uma Escola que atende aos públicos desde o Ensino Fundamental, Ensino Médio, Educação de Jovens e Adultos, de um bairro de periferia da cidade de Cariacica, região urbana do estado do Espírito Santo. A escola conta com pouca infraestrutura, mas é bem organizada, acolhedora e possui corpo gestor presente, atento e desenvolve um processo de gestão participativa e comprometida com a formação humana integral dos alunos. Mesmo com suas limitações estruturais, a escola atende a 722 alunos, sendo 19 da educação especial e conta com 74 funcionários (ESPÍRITO SANTO, 2020).

Johnny - nome fictício do sujeito deste estudo - cursa $08^{\circ}$ ano do Ensino Fundamental - Anos Finais, tem 15 anos e requer um profissional especializado durante todo período de permanência no ambiente escolar, que o atende na sala de aula regular, para favorecer sua interação. É surdocego congênito. Possui laudo que atesta catarata congênita com cegueira total e nistagmo, em ambos os olhos, e surdez congênita neurossensorial bilateral severa. Frequenta o ensino regular desde a pré-escola, porém não teve atendimento de profissional especializado na área da surdocegueira, recebendo somente assistência dos professores e de cuidadores.

Até os 2 anos de idade Johnny não engatinhava, emitia sons apenas quando chorava e passava a maior parte do tempo parado sem se movimentar. Foi acompanhado pela Associação de Pais e Amigos dos Excepcionais (APAE), para atendimento fonoaudiológico e fisioterapia. Suas necessidades especiais foram percebidas paulatinamente, primeiro a cegueira, depois a surdez e dificuldade de andar, habilidade conquistada aos 4 anos. Usou fraldas descartáveis até oito anos de idade. Seu contato com o pai biológico se deu apenas até a idade de 1 ano. Aos 4 anos, foi matriculado em uma escola de Educação Infantil. Apresentava comportamento muito agitado, agressivo e de difícil interação, pois tinha dificuldades para se comunicar.

Em 2015, passamos a nos conhecer e interagir, quando foram observadas suas características comportamentais. O aluno vagava pelo pátio da instituição tropeçando nas colunas e objetos, o que lhe causava dores e 
desconfortos. Inconformada com a rotina angustiante daquela criança, a professora nos pediu ajuda. Tensão, angústia e ansiedade foram os sentimentos que emergiram no primeiro contato com ele. Ao iniciarmos os trabalhos, nos deparamos com uma criança frágil, desconfiada e um tanto agressiva. Inicialmente fizemos observações de sua rotina. Seu caso nos desencadeou um enorme sentimento de impotência e dor, pois ali estava um sujeito necessitado de compreensão e de se fazer compreendido, percepções que the foram negadas não por descaso, mas por falta de conhecimento sobre suas limitações.

Devido à ausência de estímulos sensoriais nas primeiras fases de desenvolvimento, enfrentou grandes dificuldades de interagir, não tem uma forma de comunicação definida, nem uma língua estabelecida. Apesar dos limites que a vida the impôs, Johnny demonstra vontade de aprender e conhecer o mundo.

Para desenvolver o processo de interação e ensino de Johnny foram realizadas entrevistas como os pais e professores, observados o seu comportamento nos diversos espaços escolares. Finalmente foram pensadas e elaboradas as atividades escolares visando sua inclusão no espaço educacional e a satisfação do seu desejo de aprender.

Este estudo tem como objetivo geral avaliar as contribuições da estratégia pedagógica Comunicação Aumentativa e Alternativa para o ensinoaprendizagem de um aluno com surdocegueira congênita.

Este artigo está estruturado em 7 capítulos: o primeiro se trata da introdução; o segundo é uma análise da educação de surdocegos no Brasil; o terceiro compreende a metodologia adotada para se desenvolver o estudo; o quarto apresenta os resultados e as discussões; o quinto está pautado nos principais resultados com a intervenção pedagógica da CAA; o sexto as considerações finais e o sétimo as referências bibliográficas.

\section{Educação de surdocegos no Brasil}

Segundo Dias (2012), foi Nice Tonhozi Saraiva, quem realizou o primeiro trabalho na área da surdocegueira no Brasil. Nice visitou a Perkins School, nos 
Estados Unidos, por volta do ano de 1960, para buscar conhecimentos e formação. Retornando ao Brasil, a professora, em parceria com Neusa Basseto, conseguiu abrir a primeira escola para pessoas com surdocegueira no Brasil. No ano de 2005, o campo surdocegueira passou a ser incluído no censo escolar divulgado pelo Instituto Nacional de Estudos e Pesquisas Educacionais Anízio Teixeira - INEP, no qual acessamos os dados sobre os alunos com surdocegueira, matriculados em escolas da rede de ensino regular.

Farias (2015) acrescenta, também, que o censo de 2013 aponta a existência de 843.342 alunos com deficiências matriculados em escolas brasileiras, sendo 596 com surdocegueira. Após uma nova busca no censo escolar do ano de 2015, último disponível, com 7.856 casos cadastrados como deficiências múltiplas, 173 apresentavam cegueira ou baixa visão associados à surdez ou à deficiência auditiva. As deficiências apresentadas caracterizam a surdocegueira quando concomitante, sendo, então, deficiência única, ainda que exista outra deficiência associada.

A criança com surdocegueira tem seus direitos garantidos como qualquer outra em fase escolar, segundo determina a Lei de Diretrizes e Bases da Educação (LDB), no Capítulo V, que trata sobre a educação especial, cujo artigo 58 esclarece: "Entende-se por educação especial, para os efeitos desta Lei, a modalidade de educação escolar oferecida preferencialmente na rede regular de ensino, para educandos com deficiência, transtornos globais do desenvolvimento e altas habilidades ou superdotação " (BRASIL, 2013, s/p).

A Lei Brasileira de Inclusão, $n^{\circ}$ 13.146, de 06 de julho de 2015, conhecida como Estatuto da Pessoa com Deficiência, aponta, em seu primeiro artigo, seu objetivo: "assegurar e a promover, em condições de igualdade, o exercício dos direitos e das liberdades fundamentais da pessoa com deficiência, visando à sua inclusão social e cidadania." (BRASIL, 2015c, p.19).

Conforme o Decreto $n^{\circ} 7.612 / 2011$, o qual institui o Plano Nacional dos Direitos da Pessoa com Deficiência - Plano Viver sem Limite, no artigo 5 , prevê-se que "A União prestará apoio técnico e financeiro aos sistemas públicos de ensino dos Estados, Município e Distrito Federal e a instituições comunitárias, confessionais ou filantrópicas sem fins lucrativos". Diante disso, a 
União deve garantir "III - formação continuada de professores, inclusive para o desenvolvimento da educação bilíngue para estudantes surdos ou com deficiência auditiva e do ensino do Braille para estudante cego ou com baixa visão".

No ano de 2020, o Decreto 10.502/2020 assinado pelo Presidente da República, Instituiu a política nacional de educação especial, equitativa, inclusiva e com aprendizado ao longo da vida. O decreto dispõe que:

Fica instituída a Política Nacional de Educação Especial: Equitativa, Inclusiva e com Aprendizado ao Longo da Vida, por meio da qual a União, em colaboração com os Estados, o Distrito Federal e os Municípios, implementará programas e ações com vistas à garantia dos direitos à educação e ao atendimento educacional especializado aos educandos com deficiência, transtornos globais do desenvolvimento e altas habilidades ou superdotação (BRASIL, 2020, p.1).

Como se percebe nas pesquisas e estudos relacionados às políticas educacionais para as pessoas com surdocegueira, podemos compreender as dificuldades desse público em se relacionar no mundo e com o mundo e para exercer sua cidadania. Em vista disso, é fundamental o apoio da família e da sociedade para que a inclusão desses sujeitos realmente aconteça e assim possam constitui-se sujeitos de direitos.

Surdocegueira: uma deficiência singular

A surdocegueira é uma deficiência única causada por perda parcial ou total da visão e audição (AGOSTINO; COSTA, 2006; GALVÃO; MIRANDA, 2013).

Segundo o Grupo Brasil (2005, p. 2) a surdocegueira:

[...] é uma deficiência singular que apresenta perdas auditivas e visuais concomitantemente em diferentes graus, levando a pessoa com surdocegueira a desenvolver diferentes formas de comunicação para entender e interagir com as pessoas e o meio ambiente, para ter acesso a informações, uma vida social com qualidade, orientação, mobilidade, educação e trabalho [...] (GRUPO BRASIL, 2005, p. 2).

Essa limitação é subdividida em quatro formas: 1) surdocegueira total, 2) surdez profunda e baixa visão, 3) surdez moderada e baixa visão e 4) surdez moderada e cegueira. Além disso, também pode ser classificada em adquirida, 
quando a pessoa torna-se deficiente, no decorrer de sua vida, após o desenvolvimento de uma língua oral ou sinalizada; ou congênita, quando a pessoa nasce ou torna-se deficiente precocemente, antes da aquisição de uma língua, de habilidades comunicativas ou cognitivas, impossibilitando sua compreensão de mundo (REYES, 2004; CADER-NASCIMENTO; COSTA, 2010; BOAS et al., 2012), sendo essas as características do aluno, sujeito deste estudo.

Farias (2015) explica que a deficiência pode ocorrer de diferentes formas: nasce-se com surdez e perde-se a visão; nasce-se com cegueira e perde-se a audição; ou perde-se a visão e a audição ao longo do tempo. Estes dois períodos da surdocegueira, definidos como pré-linguístico e póslinguístico, alteram o desenvolvimento e a interação da pessoa surdocega em seu meio de convívio tornando necessário o atendimento especializado, pois "só observando como ele capta, extrai, integra, armazena, combina, elabora, planifica e comunica informação é que podemos antever se a aprendizagem ocorreu ou não" (ALMEIDA, 2008, p. 60; FARIAS, 2015).

Segundo Reyes (2004), Maia (2004) e Cambruzzi (2007), são várias as causas da surdocegueira congênita, o nascimento prematuro, baixo peso (geralmente relacionado à prematuridade), anoxia ou trauma, genética, infecções transmitidas por parasitas, citomegalovírus, toxoplasmose, bactérias ou vírus como rubéola congênita, meningites e síndromes diversas. Entre as síndromes, a da rubéola congênita é considerada a causa principal da surdocegueira congênita no mundo, devido à qual, durante a gestação e ou primeiro trimestre, pode afetar o feto, causar o aborto ou anomalias congênitas (REYES, 2004; MAIA 2004; CAMBRUZZI 2007). Em decorrência dessas características, consideradas classificatórias sobre a surdocegueira congênita e como nem todas as pessoas se comunicam da mesma forma, através da fala, por exemplo, há casos como dos indivíduos com surdocegueira congênita que demandam formas diferenciadas de comunicação para que possam compreender e se fazerem compreendidos.

Para Maia (2011, p.42): 
A necessidade de uma criança com surdocegueira congênita é a aquisição de um sistema de comunicação mais formal, por exemplo: língua de sinais, alfabeto manual e a escrita para desenvolver uma linguagem mais ampla. Geralmente, ela tem uma comunicação não simbólica como chorar, sorrir, movimentos corporais, que expressem inicialmente, suas necessidades, estas são desenvolvidas em suas interações sociais (MAIA, 2011, p. 42).

Em meio a esta questão, emergiu a necessidade de buscar diferentes formas de comunicação para o indivíduo mencionado. A Comunicação Aumentativa e Alternativa (CAA) surge como uma ferramenta relevante, não somente para o ensino-aprendizagem do aluno surdocego congênito, mas também para sua Orientação, sua mobilidade e interações sociais.

\section{Comunicação aumentativa e alternativa}

A comunicação é um meio pelo qual se expressam sentimentos, desejos, ideias, pensamentos. Recebem-se e transmitem-se informações, por meio do qual ocorrem as interações com o meio social, "Quando uma mensagem deve ser transmitida, tipicamente as pessoas utilizam a linguagem que, quer falada, escrita, ou por sinais, envolve um sistema que transmite um significado" (BOONE; PLANTE, 1994, p. 83). A comunicação aumentativa possibilita, e suplementa, a fala, a alternativa envolve gestos, expressões faciais e corporais, de pessoas impossibilitadas de usar uma linguagem oral (NUNES, 2001).

Segundo Farias (2015, p.131):

[...] a comunicação é a chave da inserção social das pessoas surdocegas no ambiente sociocultural no qual vivem. Por esta razão, tudo que estiver relacionado com a comunicação é objeto de maior interesse, por parte dos profissionais, das famílias e principalmente das próprias pessoas surdocega, na busca de sistemas de comunicação mais eficazes (FARIAS, 2015, p.131).

No caso de alunos com surdocegueira congênita, pode-se usar a comunicação aumentativa para complementar, ou compensar, a deficiência da fala sem substituí-la totalmente, já a comunicação alternativa ocorre quando se usa outro meio para se comunicar, ao invés da fala, fala ausente ou não funcional, substituindo-a para que o aluno possa adquirir conhecimento e 
autonomia. Segundo Ferreira, Ponte e Azevedo (1999), a Comunicação Aumentativa e Alternativa facilita o processo de desenvolvimento da linguagem, bem como das competências comunicativas: "é todo o gênero de comunicação que aumente a fala, sendo que inclui o uso de formas não faladas para completar ou suprimir a fala" (FERREIRA, PONTE; AZEVEDO, 1999, p. 21).

Desse modo, Nunes (2001) afirma que as formas alternativas de comunicação são diversas, tais como, o uso de gestos manuais, de expressões faciais, corporais, símbolos gráficos, fotografias, desenhos, figuras, alfabeto, bem como computadores e outros, para realizar a comunicação de pessoas impossibilitadas de usar a linguagem verbal. Estes recursos ajudam as pessoas sem linguagem oral a realizar a comunicação face a face (NUNES, 2001; SAMESHIMA, 2011). Destacamos a importância da CAA para os indivíduos surdocegos, pois trata-se de uma ferramenta que favorece sua acessibilidade ao conhecimento, visto que, por eles terem dificuldades em se comunicar da forma usual, foi Ihes impedida a aquisição do processo de aprendizado, usualmente realizado nas escolas de ensino regular (BROWNING, 2009).

Sobre essas reflexões, é importante trazermos Ponte (2009), para quem este tipo de estratégias deve ser usado o mais cedo possível, para permitir o desenvolvimento da autonomia e a participação nas atividades da escola.

No que diz respeito ao processo de comunicação, Rodbroe e Andreassen (2007, p.3) apresentam valiosa discussão:

Ao falar com outra pessoa, você precisa "estar em contato" com ela. "Estar em contato" significa que ambos estão prestando atenção um no outro e no que a outra pessoa quer compartilhar, bem como ao tentar organizar os seus próprios pensamentos. Durante o processo de comunicação, os acompanhantes se dão feedback, de modo que os dois passem por experiências que podem ser vistas, acolhidas e compreendidas entre ambos. (RODBROE; ANDREASSEN, 2007, p.3, grifo do autor).

Por esse motivo torna-se necessário apresentar várias formas de comunicação para que o aluno possa definir a qual, ou as quais, ele responde melhor. O elenco de formas alternativas de comunicação torna pertinente a citação de Almeida (2015, p.126), para quem: 
[...] o surdocego é quem determina a melhor forma de comunicação a ser estabelecida para o seu desenvolvimento. Julga que a necessidade de ampliação destas formas de comunicação ainda precisa ser desenvolvida pelos profissionais para que ofereçam aos surdocegos opções outras de acesso às informações, e assim, decidirem por aquela, ou aquelas que melhor se adeque $(m)$ às suas próprias necessidades e especificidades (ALMEIDA, 2015, p.126).

Para que a comunicação seja realmente estabelecida com o uso dessas ferramentas, torna-se necessário que esse aluno surdocego tenha acesso às diversas formas de comunicação, um ambiente acessível e contato com o profissional Instrutor Mediador (IM), este profissional, além de apresentar as diversas formas de comunicação, adaptações de materiais, tornará o ambiente acessível, percebendo e mediando quais formas de comunicação o aluno se adapta e a melhor forma de usá-las.

O instrutor mediador no processo de ensino-aprendizagem de pessoas surdocegas congênitas

O Instrutor Mediador, por compor a equipe educacional, deve estar capacitado para buscar estratégias norteadoras para o desenvolvimento e a aprendizagem dos indivíduos com surdocegueira, cabendo a ele planejar, e executar, atividades que desenvolvem a percepção cognitiva e comunicativa para o nível de cada aluno. O mediador deve possuir conhecimento das formas de comunicação, acessibilidade do ambiente, Orientação e Mobilidade, sendo importante uma formação pedagógica, vez que, dependendo do caso, o Mediador age como se fosse os olhos, os ouvidos e a boca do surdocego.

Porém, há muitos casos onde indivíduos surdocegos são deixados à margem da sociedade, por falta de conhecimento dos familiares e até mesmo das autoridades governamentais. Isso também se dá pela falta de profissionais especializados para lidarem com esse tipo de deficiência nas séries iniciais, podendo colocar em risco o desenvolvimento, como um todo, desses sujeitos. A aprendizagem ocorre de forma mais efetiva nas séries iniciais, por isso, a intervenção deve ser realizada, nesse período, para que, no futuro, a aprendizagem não seja comprometida (CERCIFAF, 2009, p.175).

No processo de mediação que se estabelece entre os sujeitos, a interação se apresenta como base para o desenvolvimento 
da linguagem, da aprendizagem e da aquisição de uma língua que, muitas vezes, acaba por não se estabelecer no ambiente familiar, uma vez que os membros da família do surdocego não encontram ou desenvolvem outras formas de comunicação que não sejam a língua oral (ALMEIDA, 2015, p. 175).

Vemos, nesse caso, que a intervenção dos pais é de extrema importância para os sujeitos surdocegos, pois são eles que interagem no dia-adia com eles (CERCIFAF, 2009), porém, os familiares não têm capacitação profissional para gerir o aprendizado social desses indivíduos e, por isso, a importância de um profissional capacitado que promoverá a intermediação entre o surdocego e a sociedade, visto que são eles que apresentam as formas de comunicação que podem ser a aumentativa e alternativa ou outras que thes proporcionarão a oportunidade de interagir com o meio ambiente familiar e social.

A comunicação aumentativa e alternativa como recurso de aprendizagem para pessoa com surdocegueira

A comunicação de alunos com surdocegueira ocorre de forma receptiva ou expressiva. Conforme Maia (2011), isso se dá, principalmente, por mediação de pessoas e com uso de objetos e figuras; ao receber a informação, a pessoa precisa interpretar a mensagem recebida. Para Cambruzzi (2007), podem-se utilizar pistas, como resíduo visual ou auditivo, tato ou olfato, sendo relevante o uso de todos os sentidos receptivos nas atividades desenvolvidas com o sujeito, pois o objetivo é a antecipação de todas as ações. A comunicação expressiva se dá quando a pessoa consegue transmitir suas ideias, sentimentos, ações e intenções. Segundo Maia (2011), essa comunicação pode acontecer por meio de gestos, da fala, movimentos corporais, objetos, figuras, entre outros.

Para Maia (2011), a comunicação simbólica é qualquer sistema de palavras, sinais ou objetos usados para se comunicar, organizado e desenvolvido por regras. Desse modo, o sujeito surdocego compreende a existência de um nome para cada coisa, até o momento de generalizar e classificar. $\mathrm{Na}$ fase pré linguística, compreende expressões faciais e movimentos corporais, da mesma forma, as pistas de informações que auxiliam 
na antecipação do que irá acontecer. Dessa forma, o aluno compreende que as atividades desenvolvidas têm começo, meio e fim.

Diante disso, Cormedi (2011) as representa como sendo: a) naturais e de contexto (sons ou cheiros do próprio ambiente, relativo à atividade a ser realizada); b) de movimento (movimentos feitos com a criança ou na criança);

c) táteis (a criança é apresentada pelo toque o que será feito); d) de objetos (são os objetos de referência, pode ser miniaturas ou tangíveis); e) gestuais (gestos naturais já entendidos pela criança, feitos dentro do campo visual, caso ainda haja algum, na mão ou no próprio corpo); f) de imagens (contorno de objetos, desenho, fotografias, símbolos gráficos ou pictográficos). No entanto, a comunicação concreta representacional é, para Cormedi (2011, p. 69), a passagem "de forma pré-linguística para linguística, onde o uso de objetos representacionais facilitará a abstração e a compreensão dos significados".

Então, é relevante, ao confeccionar materiais a serem usados com o aluno, valorizar os significados e a importância desses objetos. Nessa direção, Silva (2012, p. 81) salienta que:

Se nos colocarmos no lugar do surdocego, podemos imaginar como se sente diante de algo estranho, principalmente, quando é um objeto desconhecido e sem significado para ele, ou um objeto sem função definida e útil, como um pente, uma colher, que são facilmente reconhecidos (SILVA, 2012, p. 81).

Ao utilizarmos o objeto de referência, o aluno compreende que ele pode representar uma ação e antecipar o que irá acontecer. Um exemplo de objeto de referência e antecipação ocorre quando, ao tocar na miniatura de mochila do calendário de atividade diária, ele constata que a aula acabou e está na hora de ir embora.

\section{Metodologia}

Este estudo é exploratório e analítico, porque investiga, analisa e detalha os principais eventos ocorridos na vida familiar e escolar do sujeito e os principais fenômenos contemporâneos envolvidos no contexto real do campo da investigação, como recomenda Yin (2001). 
Como recomenda Freire (2010), antes de tudo, é preciso diagnosticar as necessidades dos educandos, respeitando o contexto cultural, social, afetivo e com relação ao nível de desenvolvimento que apresenta seus conhecimentos em leitura e escrita. Assim, pudemos conhecer as habilidades e os interesses do aluno e a prática dos educadores, por meio dos métodos diagnósticos descritos abaixo, que também sinalizaram como deveriam ser aplicadas as práticas pedagógicas que deveriam atender às demandas cognitivas e afetivas do aluno, que seguiram a seguinte processualística: 1) Observação geral no pátio, em aula e na sala de recursos educacionais, desde que o aluno chegava à escola, no lanche, idas ao banheiro e no intervalo das disciplinas, como desenvolvia as atividades propostas na sala de recurso. 2) Análise de relatórios relacionados ao desenvolvimento das atividades, comportamentos do aluno, exames médicos. 3) Entrevista com a mãe para conhecer as características de sua doença desde a gestação e fatos dos primeiros anos escolares. 4) Avaliação diagnóstica que utilizou os três procedimentos anteriores. Foram sistematizados seus anseios, desejos, afinidades e rejeições e formas de comunicação. 5) Entrevistas com professores para compreender como ocorria sua comunicação e as práticas de ensino e, como eles percebiam as mudanças comportamentais do aluno, a partir das práticas da intervenção, que foram registradas com filmagens e fotografias.

A pesquisa foi realizada na Escola Nossa Senhora Aparecida de Ensino Fundamental, Ensino Médio, Educação de Jovens e Adultos, Atendimento Educacional Especializado com turno e contra turno. Localizada no bairro Oriente, periferia da Cidade de Cariacica, no estado do Espírito Santo.

O sujeito desta pesquisa é matriculado no $8^{\circ}$ ano do Ensino Fundamental, possui 15 anos de idade e será identificado pelo nome de Johnny. O aluno é surdocego congênito, em razão de ter nascido prematuro. Possui laudo de visão que atesta a catarata congênita com cegueira total e nistagmo, em ambos os olhos, e laudo de audição que atesta surdez congênita neurossensorial bilateral severa.

Os dados produzidos foram comparados e analisados na seguinte perspectiva: o desenvolvimento apresentado pelo aluno antes e após o uso da 
Comunicação Aumentativa e Alternativa. Os contatos anteriores com o aluno permitiram obter registros das feições que ele apresentava antes da intervenção, que já se encontravam na pasta escolar do aluno. Foram também providenciados novos relatórios, exames médicos, fotos e filmagens, que mostraram como era o desenvolvimento do aluno antes e depois da intervenção com o uso da CAA. As informações que precederam a intervenção foram importantes para desnudar como se processava o seu desenvolvimento e sua forma de comunicação. Para possibilitar as comparações de forma relevante, todas as observações (anteriores, concomitantes e posteriores à intervenção, com uso da CAA) foram registradas em relatórios e destacados os pontos importantes que revelaram se houve, ou não, desenvolvimento na aprendizagem do aluno, cujos resultados se deveram ao uso da CAA e evidenciaram seu processo de interação na sala de aula com professores e colegas e seu progresso educacional.

\section{Resultados e discussões}

As observações evidenciaram que Johnny nunca havia sido estimulado em conformidade com suas necessidades pessoais e educacionais, pois não se estabelecia a comunicação entre o aluno e o mundo. Os toques físicos eram repelidos, demonstrando que não fazia uma comunicação simbólica, própria de quem não tem domínio de uma língua (MAIA, 2011). Não havia um profissional especializado para fazer seu acompanhamento e ele se mantinha totalmente alheio ao processo pedagógico. $\mathrm{Na}$ sala de Atendimento Educacional Especializado observamos que não havia atividades baseadas nas especificidades dele, não sendo pensadas com a sequência devida e nem adaptadas. Portanto, não havia a interação social tão importante para seu desenvolvimento cognitivo e emocional.

A entrevista realizada com a mãe revelou que seu desenvolvimento foi parco, não emitia outro som a não ser o choro e passava a maior parte do tempo inerte. Ela nada conhecia sobre CAA. Assim ele não foi precocemente estimulado, fato que agravou sua capacidade de comunicação. Todavia, as atividades desenvolvidas durante a intervenção foram fundamentais para o 
desenvolvimento do filho, uma vez que percebeu que "mudou tudo na vida do filho e da família". Também menciona que ele passou a saber "coisas novas", como "dizer sim", "dizer não", ser participativo, presente, identificar as pessoas, se apresentar, cumprimentar, ser educado, demonstrar sentimentos, afeto e carinho.

Os professores se sentiam angustiados e inseguros antes da intervenção, pois não sabiam como agir diante das dificuldades de Jhonny. Contudo, relataram que perceberam o seu desenvolvimento pessoal e educacional, durante e após a intervenção com a CAA. Relataram que era sua primeira experiência com surdocego. Afirmaram que após o conhecimento da CAA, o aluno passou a reconhecê-los e aprendeu a função de cada um na instituição, e que Jhonny manifestou interesse pelas atividades escolares, melhorou a autoestima e a interação com os colegas passou a fazer sentido. Consideraram também que a CAA seu trabalho ficou mais prazeroso, pois "o aluno obteve acesso ao conhecimento através de adaptações dos conteúdos condizente a sua necessidade" e opinaram que a CAA é de extrema relevância na aprendizagem do aluno, pois antes da intervenção não podiam afirmar que o aluno estava incluído no processo escolar. Observaram também que o aluno passou a expressar seus sentimentos e transmitir carinho aos colegas, que a família se fez mais presente, dando-Ihe o apoio necessário. Um dos docentes afirmou: "Sabe o que é seu aluno tocar em você, sentir seu cheiro, falar seu nome através de uma forma de comunicação e te pedir um abraço? Essa experiência não tem preço, é inesquecível”. A intervenção permitiu ao Johnny o contato com internalização e adaptação da Libras tátil, braille, interpretação tátil, comunicação háptica, e Comunicação Aumentativa e Alternativa. Importante ressaltar a efetiva participação do sujeito na confecção dos materiais, estratégia que favorece o manuseio e a compreensão do objetivo educativo da atividade e desperta o interesse pelo objeto e, consequentemente, pelo aprendizado. 


\section{Principais resultados com a intervenção pedagógica CAA:}

A aproximação inicial com o aluno foi um pouco conturbada, pois ele não estava acostumado a interagir com pessoas que não faziam parte da sua rotina educacional. Então, foi importante estabelecer uma intimidade entre os saberes curriculares fundamentais e sua experiência social como orienta Freire (2010). Nos primeiros contatos, ele se mostrava agitado, agressivo, o que dificultava a interação. Não tinha noção de si e desconhecia que tudo pode ser nomeado e tem significado. Não tinha noção do que significava a mãe (família) e os alimentos; nem convivência social e expressão de afetos. A descoberta desses elementos causou-Ihe estranhamento. Reconhecer que existia um ser que não percebia tais saberes, nos provocou espanto e questionamentos: quais seriam seus sentimentos? Sabemos que há possibilidades para ele, pois conhecemos educadores surdocegos congênitos, que atuam no mundo do trabalho.

A seguir, são apresentadas as atividades pedagógicas e discutidos seus respectivos resultados.

1) O Calendário de presença (Figura 1) contém o nome do aluno em relevo, uma imagem adaptada ao tátil que representa a sala de aula e um boneco objeto de referência, que Ihe representa. Tem função de confirmar sua presença, quando o professor faz a chamada, e o aluno estabelece uma ponte entre o concreto e o abstrato, como recomenda Cormedi (2011). Sua participação na confeç̧ão dos materiais foi relevante, pois o manuseio de objetos junto com o mediador favoreceu a construção mental da imagem e o fez internalizar sua função. Nesse aspecto, como explica Vygotsky (2007) o aluno passou por transformações que Ihes permitiram estabelecer as conexões cerebrais e reconstruir internamente uma operação externa. 

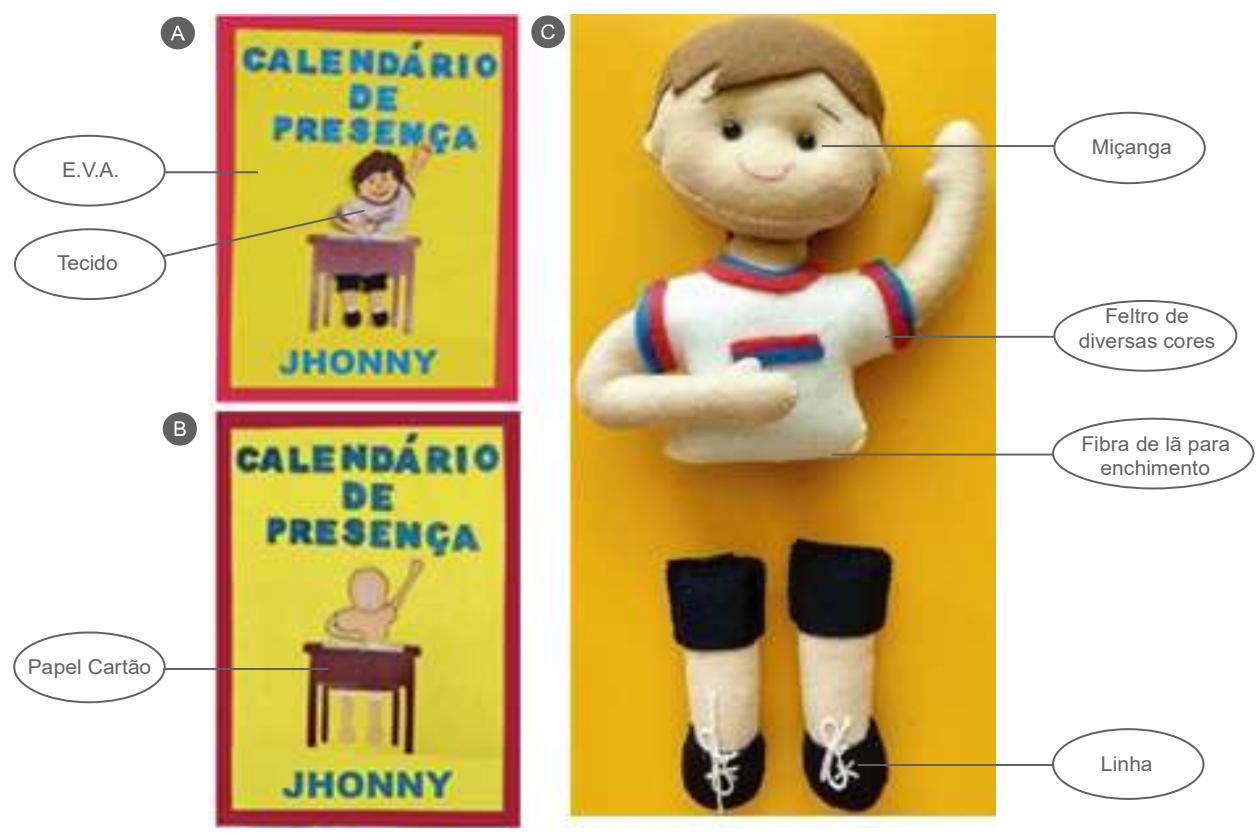

Figura 1: Calendário de presença. Fonte: Elaborada pela autora. Ano 2019.

Na sequência, ele passou a manusear o alfabeto em Língua Portuguesa juntamente com o alfabeto em braille, para que pudesse introduzir futuramente habilidades de leitura e escrita. Essa também é uma forma de comunicação aumentativa, que não substitui a comunicação, mas a amplia. Foi importante apresentar a tradução em braille de todas as atividades desenvolvidas.

$\mathrm{Na}$ linguagem braile o sistema de escrita em relevo é constituído por 63 sinais formados a partir de um conjunto matricial de seis pontos, o espaço ocupado pelos pontos chama-se cela. A cela é definida por uma matriz com 2 colunas e 3 linhas e cada qual possui 6 casas, cada casa combinada forma uma letra do alfabeto, como apresentam as Figuras 2, 3 e 4. 


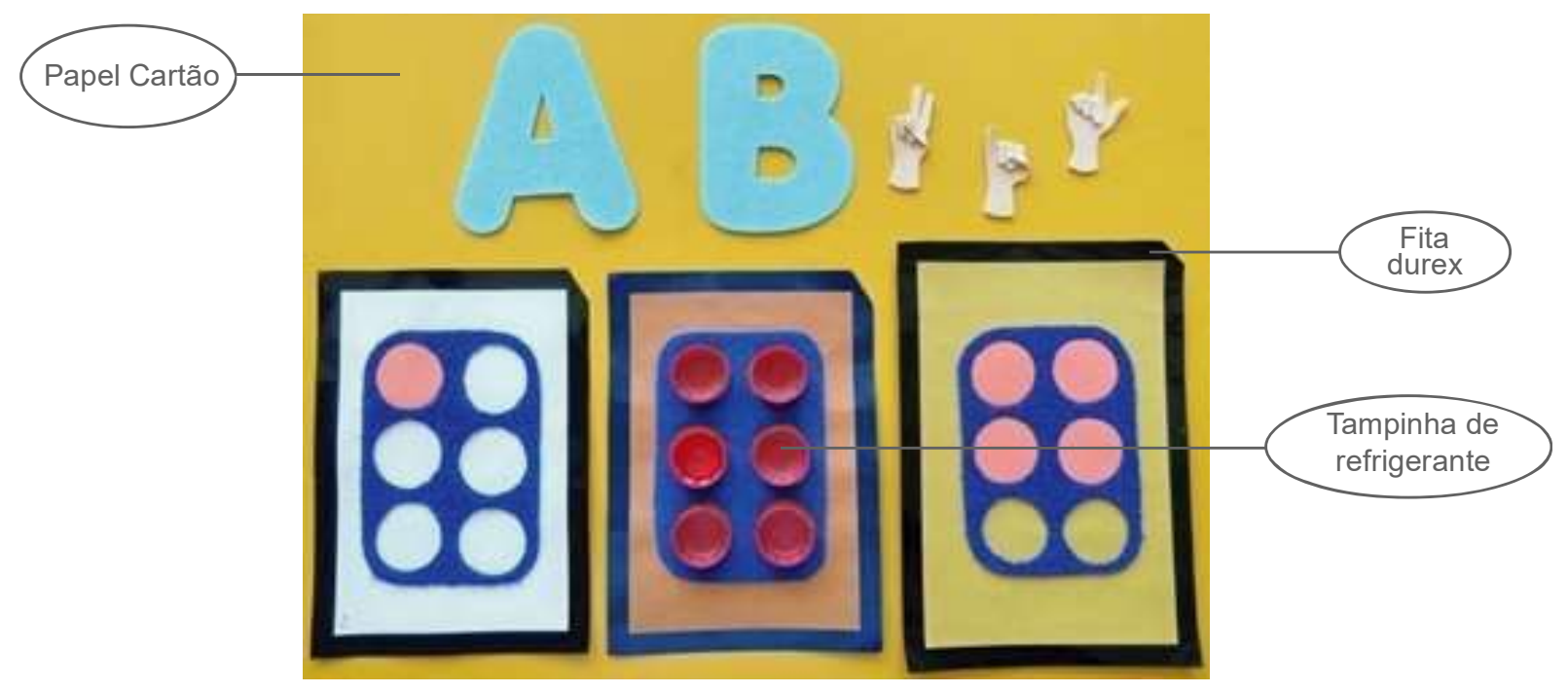

Figura 2: Celas para uso do braille. Fonte: Elaborada pela autora. Ano 2019.

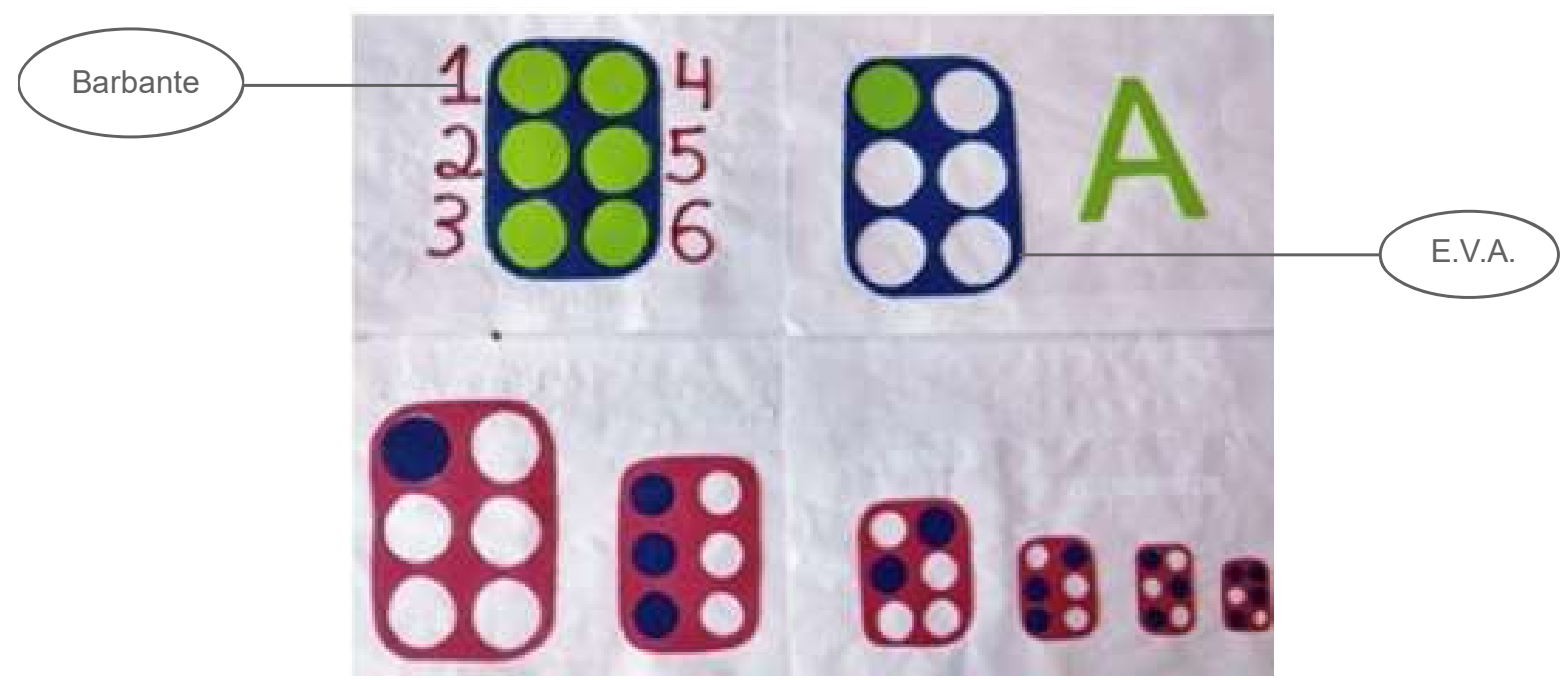

Figura 3: Celas para uso do braille. Fonte: Elaborada pela autora. Ano 2019.

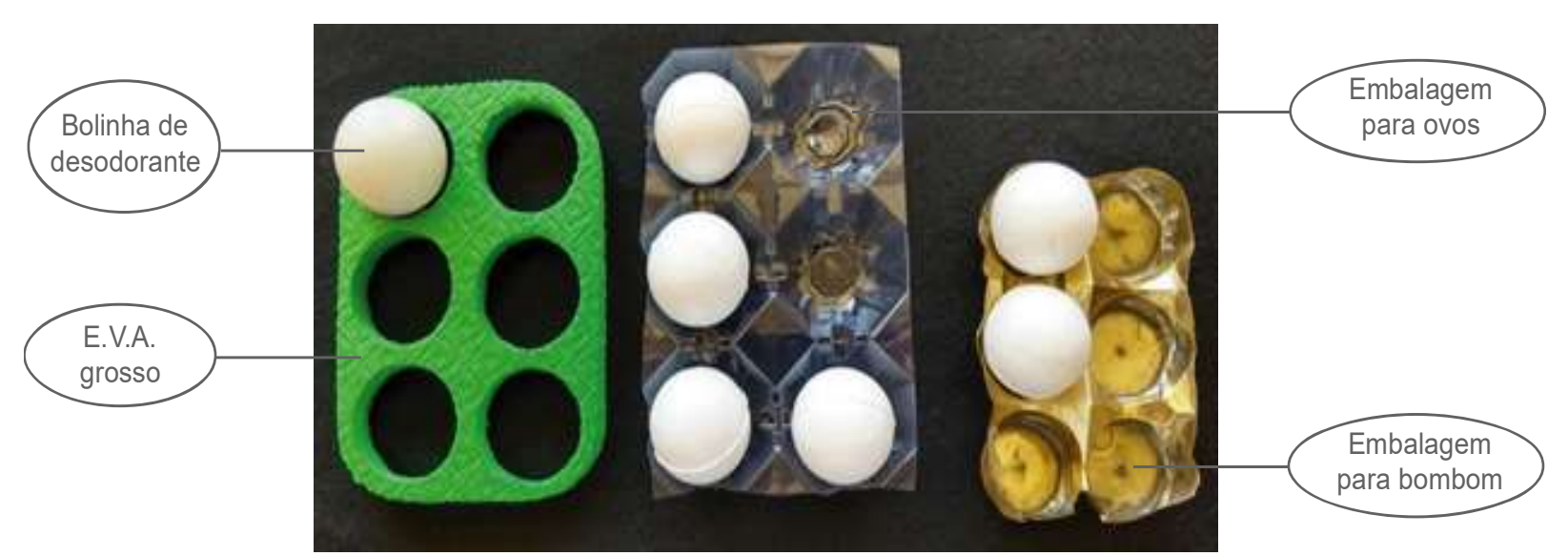

Figura 4: Celas- em diversos materiais para uso do braile. Fonte: Elaborada pela autora. Ano 2019. 
Nesse contexto, houve momentos que Jhonny não aceitava bem as atividadedes, uma vez que não compreendia o que deveria ser feito, fato que exigiu repetições e a busca de outros materiais e outras formas de comunicação ou outra metodologia. Foi necessária muita muita persistência e repetições sucessivas, com o uso "[...] da mesma sequência de sinais, nas mesmas situações para que a criança assimile e consiga compreender e comunicar-se expressando sua vontade" (SILVA, 2012, p. 49).

2) Calendário diário de aula (Figura 5) foi composto por 7 repartições, que representaram as 5 de disciplinas curriculares, o horário de recreio e uma repartição vazia, para representar o término das atividades que continha uma mochila em miniatura, indicando a hora de voltar para casa. Essa atividade permitiu-lhe desenvolver a noção de tempo e os contatos iniciais com conteúdos curriculares. Muito mais que um instrumento de comunicação, esse calendário desenvolveu uma linguagem, como orienta Cormedi (2011). Favoreceu que o aluno compreendesse a sequência da sua rotina diária e possibilitou que os professores se cerificassem de sua presença na escola. Os objetos de referência comunicaram por meio de objetos as atividades realizadas.

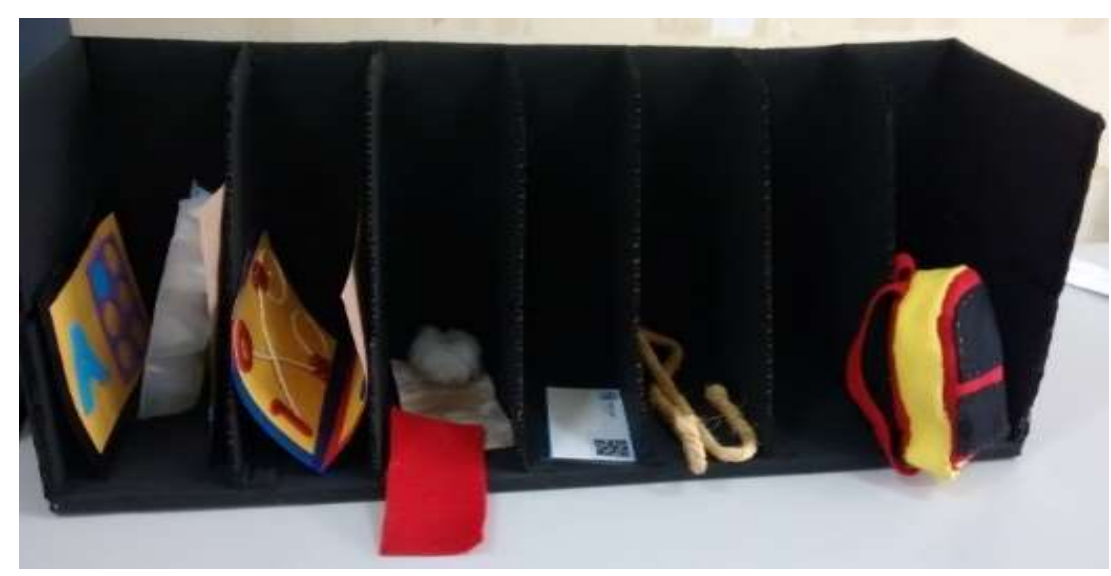

Figura 5: Calendário diário de aulas. Fonte: Elaborada pela autora. Ano 2019. 


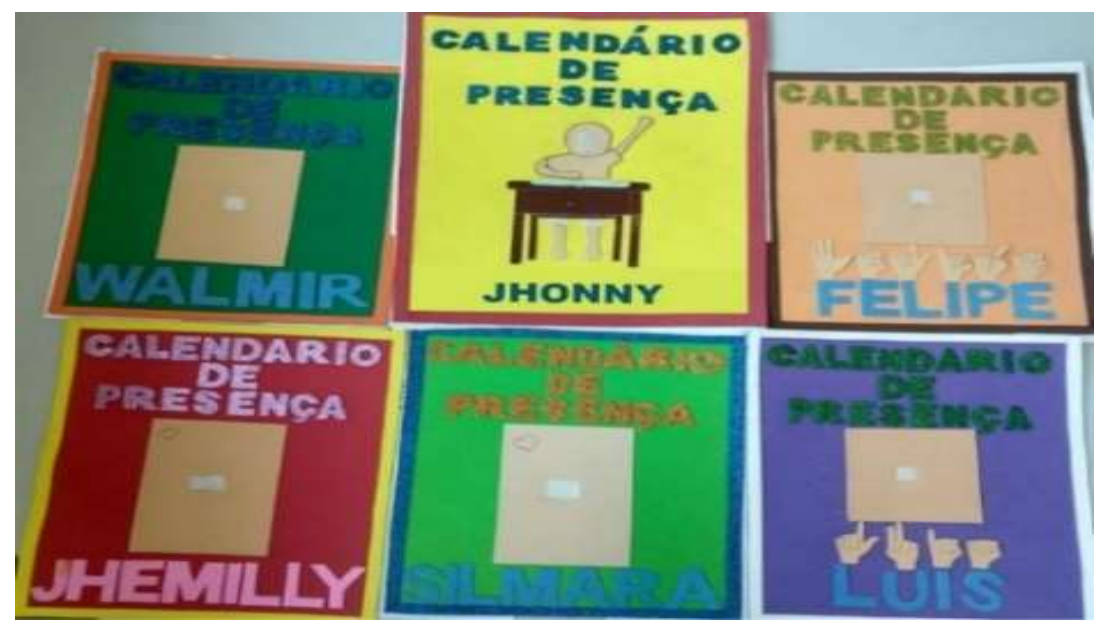

Figura 6: Calendário de presença. Fonte: Elaborada pela autora. Ano 2019.

A Figura 6 consiste em outro tipo de calendário de presença, que pode ser adaptado para alunos com outras NEE, que necessitam da comunicação alternativa para sua comunicação.

3) Calendário semanal de aulas favoreceu a sua compreensão e adaptação à rotina semanal, e saber as disciplinas que seriam estudadas. Este material possibilitou a aquisição da noção de tempo e compreensão de que cada disciplina tem seu conhecimento específico.

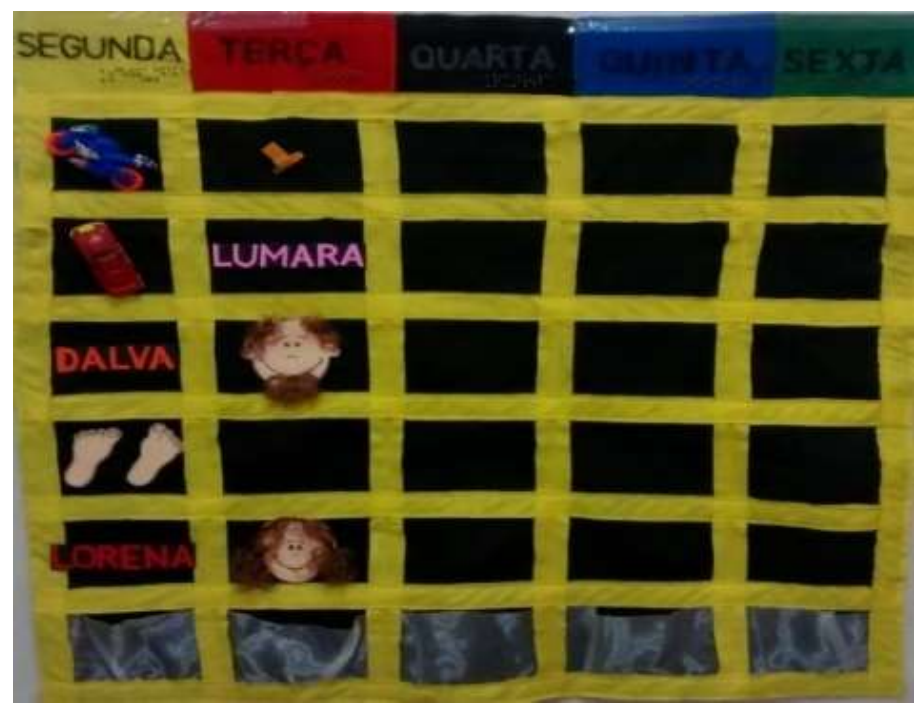

Figura 7: Calendário semanal de aulas. Fonte: Elaborada pela autora. Ano 2019.

O calendário é composto pelos dias da semana em tinta e em braille, cada dia tem um objeto de referência do professor. Por ter sido coparticipante 
de sua criação, ele pode identificar cada professor e associar as disciplinas em seus respectivos dias de aula. A última parte do calendário contém repartições onde são depositados os objetos, ao término de cada disciplina. Por exemplo: a moto representa o professor de matemática, ao terminar a aula de matemática, o aluno pega a moto e a posiciona na repartição vazia abaixo e, assim, sucessivamente.

4) Livro da árvore genealógica

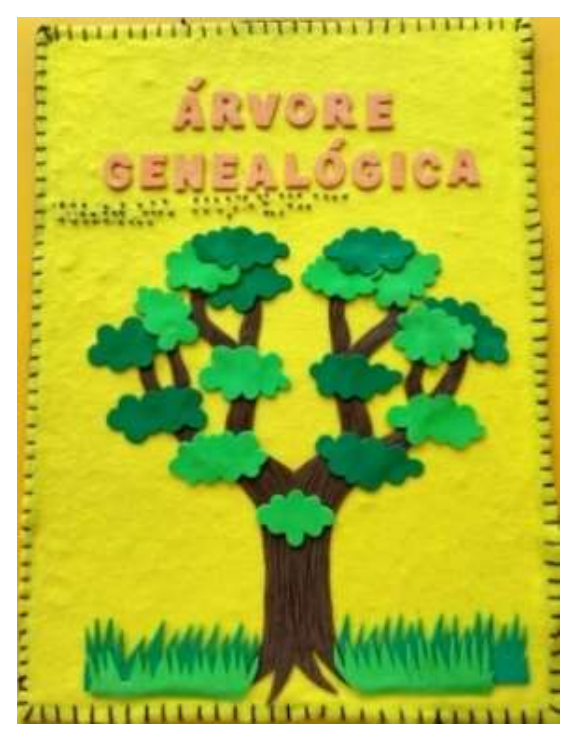

Figuras 8: Livro da árvore genealógica. Fonte: Elaborada pela autora. Ano 2019.

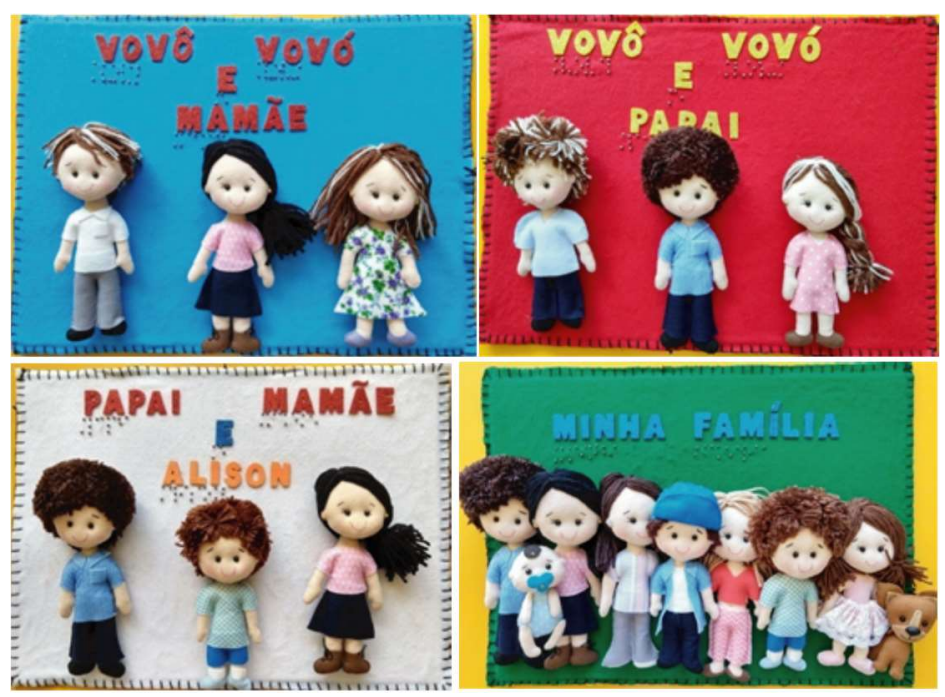

Figura 9: Estudos de parentesco e genealogia familiar. Fonte: Elaborada pela autora. Ano 2019.

Possui formato de comunicação alternativa (Figura 8) e busca estimular a noção de parentesco, aprofundar saberes sobre sua própria história e a história de seus antepassados, até seu nascimento (Figura 9). 
5) Bonecos com tamanhos diferentes

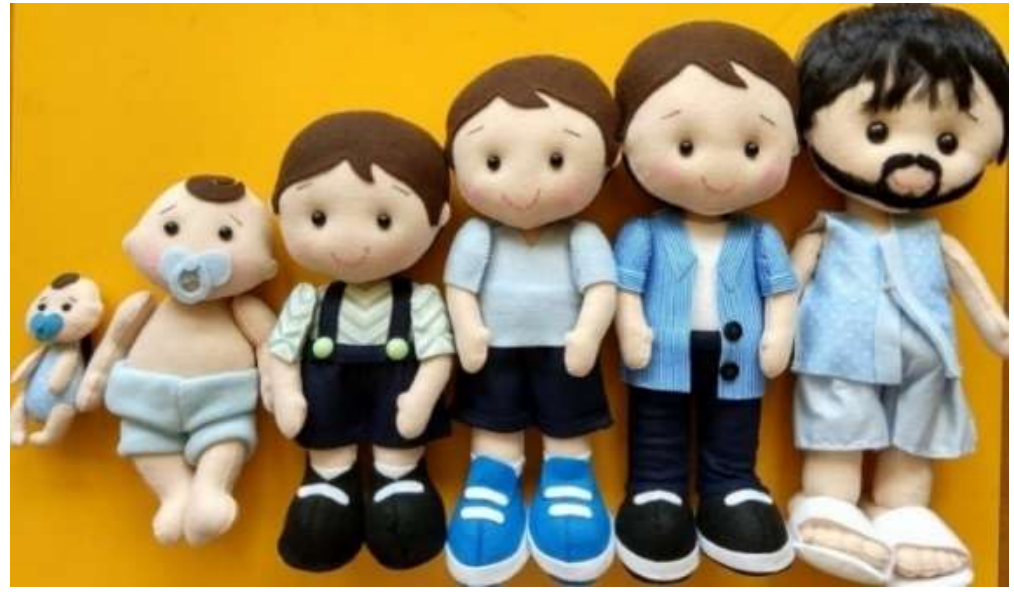

Figura 10: Bonecos demonstrando as mudanças de idade. Fonte: Elaborada pela autora. Ano 2019.

A atividade funciona como um tipo $d$

e comunicação alternativa (Figura 10). Acrescentamos essa atividade aos conteúdos já desenvolvidos para que o aluno percebesse as diferenças entre idades e, assim, pudesse compreender aspectos como nascimento e crescimento, transformações físicas, visando estimular a noção de desenvolvimento humano.

6) Bonecos pedagógicos

Esta atividade (Figuras 11 a 12), auxiliaram no ensino de conteúdos relacionados ao desenvolvimento e reprodução humana, o que permite o professor explorar diversos saberes como noção de gênero, anatomia do aparelho reprodutor, fisiologia, patologias sexualmente transmissíveis e sua prevenção, gravidez na adolescência, parto natural e cesariana, dentre outros. Importante ressaltar que o desenvolvimento dessa atividade só foi possível devido ao vínculo afetivo anteriormente estabelecido. 


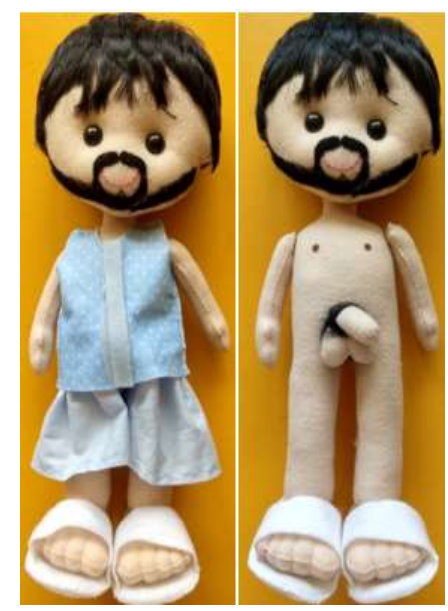

Figura 11: Bonecos pedagógicos com figuras masculinas. Fonte: Elaborada pela autora. Ano
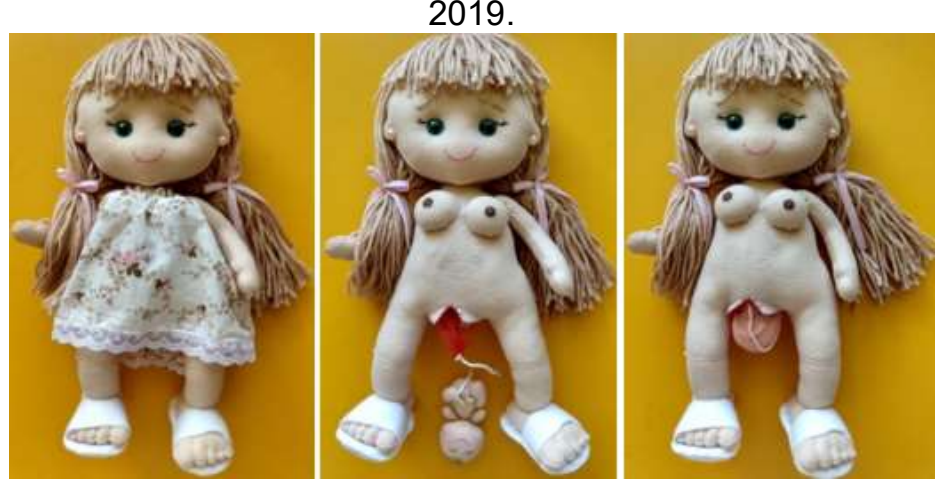

Figura 12: Bonecos pedagógicos com figuras femininas. Fonte: Elaborada pela autora. Ano 2019.

7) Portfólio de atividades

A medida que o aluno foi consolidando sua aprendizagem, confeccionamos um portfólio, para organizar as atividades e apoiar outras instituições escolares. A construção desse portfólio também contou com a participação de Jhonny. Vygotsky (2007) esclarece sobre a atenção desencadeada durante a realização das tarefas:

A possibilidade de combinar elementos dos campos visuais presente e passado (por exemplo, o instrumento e o objeto-alvo) num único campo de atenção leva, por sua vez, à reconstrução básica de uma outra função fundamental, a "memória". Através de formulações verbais de situações e atividades passadas, a criança liberta-se das limitações da lembrança direta; ela sintetiza, com sucesso, o passado e o presente de modo conveniente a seus propósitos (VIGOTSKY, 2007, p. 28, grifo do autor). 
O portfólio contribuiu para a estimulação da memória. Nessa perspectiva, ficou evidenciado que o aluno internalizou os conteúdos à medida em que foi desenvolvendo cada atividade. Esse processo foi se efetivando de modo contínuo até o fim do ano letivo de 2019.

\section{Considerações finais}

Para garantir o espaço da pessoa com surdocegueira de forma justa e igualitária, o primeiro passo é o reconhecimento de que existe amparo legal. A identificação certeira da deficiência, favorece a garantia dos direitos à educação e aos atendimentos adequados. Assim, a obrigatoriedade de suprir profissionais especializados para o AEE deve ser cumprida pela escola.

É importante a oferta de formação para profissionais que já atuam na área, possibilitando um atendimento inclusivo, proporcionando 0 desenvolvimento dos sujeitos nas suas múltiplas dimensões, intelectual, emocional e social. A preparação da escolar requer espaços acessíveis, profissionais qualificados e atendimentos educacionais especializados para atender as especificidades das necessidades presentes na sala de aula. Destacamos a relevância do apoio educacional para com os pais que, se envolvidos favorecem o desenvolvimento dos filhos.

A pessoa com surdocegueira tem potencialidades, como qualquer outra, independentemente do grau da deficiência. Este estudo constatou a importância de destinar carga horária para o profissional da área atuar durante a permanência do aluno no ambiente escolar, sob pena de ter desenvolvimento comprometido.

No banco de dados do Educasenso, da Secretaria de Educação do Estado do Espírito Santo, consta um número inferior ao da realidade, uma vez que não são todos cadastrados. É possível que isso se deva ao não reconhecimento da surdocegueira como deficiência única, fato que prejudica a exatidão do diagnóstico, resultando em laudos incorretos, onde constam outras deficiências.

Os resultados da pesquisa evidenciaram que a intervenção pedagógica com o uso da CAA contribuiu para a aprendizagem do aluno com 
surdocegueira congênita, e trouxe mudanças na comunidade escolar, influenciando na visão dos educadores e gestores e, principalmente, da sua família, que passou a acreditar nas potencialidades de Jhonny e melhorou de sua comunicação.

Apontamos a importância da estimulação da sensorialidade, pois percebemos um retorno considerável, e comprovado, através de exames de audiometria feitos antes, durante e após as estimulações, deixando evidente que impactou positivamente o aprendizado do aluno. Importante considerar a extrema relevância em estabelecer a participação ativa do aluno, em todas as fases da intervenção.

Jhonny estabeleceu formas de interpretar através da libras tátil, comunicação háptica, braille e a Comunicação Aumentativa e Alternativa, internalizou a noção de tempo, regras de convivências, afetividades, conceitos pessoais e sociais. Desse modo, comparamos o processo de aprendizado do aluno. Não poderíamos deixar de citar, também, meu crescimento como pessoa, como profissional e, acima de tudo, o prazer de dever cumprido, pois o aluno pôde dar sequência a seu aprendizado e perseguir seus sonhos, como qualquer outro sujeito da sociedade.

\section{Referências}

AgostinO, E. A. M.; COSTA, M. P. R. Aplicação de um programa para o ensino da leitura e escrita de palavras para o aluno com surdocegueira. Periódico do Mestrado em Educação da UCDB (Série-Estudos), Campo Grande, n. 22, pp. 161-173, jul./dez. 2006.

ALMEIDA, W. G. O guia-interprete e a inclusão da pessoa com surdocegueira. 2015. 188 f. Tese (Doutorado) - Programa de Pós-graduação em Educação, Universidade Federal da Bahia, Salvador, 2015.

ALMEIDA, W. G. A educação de surdocegos: novos olhares sobre a diferença. In: ALMEIDA, W. G. (Org.). Educação de surdos: formação, estratégias e prática docente [online]. Ilhéus, BA: Editus, 2015, pp. 163-194.

ALMEIDA, C. A. F. A aquisição da linguagem por uma surdocegaprélinguística numa perspectiva sociocognitiva-interacionista. 2008. $337 \mathrm{f}$. Tese (Doutorado). Brasília: Universidade de Brasília, 2008. Disponível em: http://repositorio.unb.br/bit 
stream/10482/5723/1/2008_CeliaAFAlmeida_reduzida.pdf. Acesso em: 11 maio 2015.

BOAS D. C. V.; FERREIRA L. P.; MOURA M. C.; MAIA S. R. A comunicação de pessoas com surdocegueira e a atuação fonoaudiológica. DistúrbComun, São Paulo, v. 24, n. 3, pp. 407-414, 2012.

BOONE, D. R.; PLANTE, E. Comunicação humana e seus distúrbios. Tradução de Sandra Costa, Porto Alegre: Artes Médicas, 1994.

BRASIL. Lei $n^{\circ}$ 12.796, de 4 de abril de 2013. Altera a Lei $n^{\circ} 9.394$, de 20 de dezembro de 1996, que estabelece as diretrizes e bases da educação nacional, para dispor sobre a formação dos profissionais da educação e dar outras providências. Casa Civil, 4 de abril de 2013. Disponível em: http://www.planalto.gov.br/ccivil 03/ ato2011-2014/2013/lei//12796.htm.

Acesso em: 11 de nov. 2020.

BRASIL. Lei $n^{\circ} 13.146$, de 6 de julho de 2015. Estatuto da Pessoa com Deficiência - Lei Brasileira de Inclusão. Diário Oficial [da] República Federativa do Brasil, 7 jul. 2015. Brasília, 2015c.

BRASIL. Decreto $n^{\circ} 10.502$, de 30 de setembro de 2020. Institui a Política Nacional de Educação Especial: Equitativa, Inclusiva e com Aprendizado ao Longo da Vida. Diário Oficial [da] República Federativa do Brasil. Disponível em: https://www.in.gov.br/en/web/dou/-/decreto-n-10.502-de-30-de-setembrode-2020-280529948. Acesso em: 11 de nov. 2020.

BROWNING, N. Curso sobre a comunicação alternativa: falada e escrita, [PDF]. 2009.2 Disponível em: https://www.assistiva.com.br/Palestra\%20CAA\%20Nadia\% 20Browning.pdf. Acesso em: 23 fev. 2019.

CAMBRUZZI, R. C. S. Análise de uma experiência de atitudes comunicativas entre mãe e adolescente surdocega: construção de significados compartilhados. 2007. 179 f. Dissertação (Mestrado) - Programa de Pós-Graduação em Educação Especial, Universidade Federal de São Carlos (UFCAR), São Carlos: UFSCAR, 2007.

CERCIFAF - Cooperativa de Educação e Reabilitação de Crianças Inadaptadas de Fafe (2009). O que é a Intervenção Precoce? Disponível em: www.cercifaf.pt.. Acesso em: 23 fev. 2019.

CORMEDI, M. A. Alicerces de significados e sentidos: aquisição de linguagem na surdocegueira congênita. 2011. 402 f. Tese (Doutorado) Programa de Pós-Graduação em Educação, Universidade de São Paulo, 2011.

DIAS, D. T. Contextualização Histórica. Projeto Pontes e Travessias: formação de guia-intérprete. São Paulo, 2012. pp. 4-14. 
ESPÍRITO SANTO. Secretaria de Educação do Estado do Espírito Santo. Site da secretaria de Educação do Estado do Espírito Santo. Disponível em: https://sedu.es.gov.br/. Acesso em: 12 de nov. 2020.

FARIAS, S. S. P. Os processos de inclusão dos alunos com surdocegueira na educação básica. 2015. 201 f. Dissertação (Mestrado) - Universidade Federal da Bahia, Salvador, 2015.

FREIRE, P. Pedagogia da autonomia: saberes necessários à prática educativa. Rio de Janeiro: Paz e Terra, 2010.

FERREIRA, C.; PONTE, M.M.N.; AZEVEDO, L.M.F. Inovação curricular na implementação de meios alternativos de comunicação em crianças com deficiência neuromotora grave. Lisboa: Secretariado Nacional para a Reabilitação e Integração das Pessoas com Deficiência, 1999.

GALVÃO, N. de C. S. S.; MIRANDA, T. G. Atendimento educacional especializado para alunos com surdocegueira: um estudo de caso no espaço da escola regular. Revista Brasileira de Educação Especial, Marília, v. 19, n. 1, pp. 43- 60, jan./mar. 2013.

GRUPO BRASIL DE APOIO AO SURDOCEGO E AO MÚLTIPLO DEFICIENTE SENSORIAL. Síndrome de Usher. Série: Surdocegueira e deficiência múltipla sensorial [folder], São Paulo, 2005.

MAIA, S. R. A educação do surdocego: diretrizes básicas para pessoas não especializadas. 2004. 81 f. Dissertação (Mestrado) - Universidade Presbiteriana Mackenzie, São Paulo, 2004.

MAIA, S. R. Descobrindo crianças com surdocegueira e com deficiência múltipla sensorial, no brincar. Tese (Doutorado) - Programa de PósGraduação em Educação. Universidade de São Paulo, 2011.

NUNES, L. R. d'O. de P. A comunicação alternativa para portadores de distúrbios da fala e da comunicação. In: MARQUEZINE; M.C.; ALMEIDA, M.A.; TANAKA, E. D. O. (Orgs.). Perspectivas multidisciplinares em Educação Especial II. Londrina: EDUEL, 2001.

PONTE, M. Comunicação aumentativa: mitos e preconceitos. 2009. Disponível em:

http://www.fappc.pt/ComunicacoesCongresso/Resumo\%20Margarida\%20

Ponte.pdf.. Acesso em: 23 fev. 2019.

REYES, D. A. La sordoceguera: uma discapacidad singular. Madrid: Organización Nacional de Ciegos Españoles, 2004.

RODBROE, I.; ANDREASSEN, E. Communication for DeafblindChildren: projeto países Nórdicos e Quênia e apoio de Edição FSDB/SHIA, Suécia, 2007.

SAMESHIMA, F. S. Capacitação de professores no contexto de sistemas de comunicação suplementar e alternativa. 2011. $173 \mathrm{f}$. Tese (Doutorado) - 
Universidade Estatual Paulista Júlio Mesquita Filho, Marília, 2011. Disponível em: https://repositorio.unesp.br/handle/11449/102185. Acesso em: 15 fev. 2019.

SILVA, A. M. de B. Heldy meu nome: rompendo barreiras da surdocegueira. São Paulo: Hagnos, 2012.

VIGOTSKY, L.S. A formação social da mente. 7. ed. São Paulo: Martins Fontes, 2007.

YIN, R. K. Estudo de caso: planejamento e métodos. 2. ed. Porto Alegre: Bookman, 2001.

\section{Sobre os Autores}

\section{Elzinete Maria Carvalho Machado}

maoungida@hotmail.com

Mestrado em Ciências, Tecnologia e Educação pela Faculdade Vale do Cricaré em São Mateus-ES. Licenciatura em Pedagogia pela Universidade de Uberaba-MG. Licenciatura em Artes Visuais pelo Centro Universitário de Jales em São Paulo-SP. Especialista em Atendimento Educacional Especializado pela Faculdade Luso Capixaba em Cariacica-ES, Educação Especial e Inclusiva pela Faculdade Mario Schenberg em São Paulo-SP, Libras pelo Centro de Ensino Fabra em Serra-ES, Artes e Educação pela Faculdade Mario Schenberg em São Paulo-SP, Deficiência Visual pela Faculdade Novo Milênio Vila Velha-ES. Atualmente é professora no Atendimento Educacional Especializado na área da surdocegueira na Secretaria de Estado da Educação do Espírito Santo.

\section{Desirée Gonçalves Raggi}

desireeraggi@yahoo.com.br

Agrônomia pela Universidade Federal de Viçosa. Mestrado em Pedagogia Profissional pelo Instituto Superior Pedagogico para la Educación Tecnica e Profesional Hector P. Zaldivar / Universidade Federal de Goiás (2009). Doutorado em Educação - Universidad del Norte/ Universidade Federal de Pernambuco. Exerceu a docência em duas escolas agrotécnicas (Rio Verde GO e Alegra- ES) e no Instituto Federal do ES, na área de Educação. Atualmente é professora e pesquisadora da Faculdade Vale do Cricaré. 